\title{
Ageing Testing Procedures on Lithium Batteries in an International Collaboration Context
}

\author{
Mario Conte ${ }^{1}$, Fiorentino V. Conte ${ }^{2}$, Ira D. Bloom ${ }^{3}$, \\ Kenji Morita ${ }^{4}$, Tomohiko Ikeya ${ }^{5}$, and Jeffrey R. Belt ${ }^{6}$ \\ ${ }^{I}$ Energy Storage Systems, “Advanced Technologies for Energy and Industry”, National Agency for New Technologies, \\ Energy and Sustainable Economic Development, S. Maria di Galeria (Rome),00123, Italy, mario.conte@enea.it \\ ${ }^{2}$ Electric Drive Technologies, Mobility Department, AIT Austrian Institute of Technology, Giefinggasse 2 (Vienna), \\ Austria,valerio.conte@ait.ac.at \\ ${ }^{3}$ Argonne National Laboratory (ANL), 9700 South Cass Avenue, Argonne, IL 60439 USA, ira.bloom@anl.gov \\ ${ }^{4}$ Performance Research FC-EV Research Division, Japan Automobile Research Institute (JARI), kmorita@jari.or.jp \\ ${ }^{5}$ Central Research Institute of Electric Power Industry (CRIEPI), 2-6-1 Nagasaka, Yokosukashi Kanagawaken 240- \\ 0196,Japan,ikeya@criepi.denken.or.jp \\ ${ }^{6}$ Idaho National Laboratory (INL), 2525 North Fremont, Idaho Falls, ID 83415 USA, jeffrey.belt@inl.gov
}

\begin{abstract}
The widespread introduction of electrically-propelled vehicles is currently part of many political strategies and introduction plans. These new vehicles, ranging from limited (mild) hybrid to plug-in hybrid to fully-battery powered, will rely on a new class of advanced storage batteries, such as those based on lithium, to meet different technical and economical targets. The testing of these batteries to determine the performance and life in the various applications is a time-consuming and costly process that is not yet well developed. There are many examples of parallel testing activities that are poorly coordinated, for example, those in Europe, Japan and the US. These costs and efforts may be better leveraged through international collaboration, such as that possible within the framework of the International Energy Agency (IEA). Here, a new effort is under development that will establish standardized, accelerated testing procedures and will allow battery testing organizations to cooperate in the analysis of the resulting data. This paper reviews the present state-of-the-art in accelerated life testing procedures in Europe, Japan and the US. The existing test procedures will be collected, shortly described, compared and analyzed with the goal of defining a process and a possible working plan for the establishment of an international collaboration.
\end{abstract}

Keywords: lithium batteries, battery testing procedures, electric vehicles, hybrid-electric vehicles

\section{Background and Introduction}

This is e widespread introduction of electricallypropelled vehicles is nowadays part of many political strategies and introduction plans, which clearly state the social and environmental needs and the industrial opportunities. These new vehicles, which range from hybrid electric (HEV) to plug-in hybrid electric (PHEV) to pure electric (EV), will rely on a new class of advanced storage batteries, which are able to meet different technical and economical goals. The behavior of these new storage systems will be tailored for the specific requirements for the given application. This will ensure that the performance characteristics, cycle life and cost will be similar to those of conventional vehicles. In particular, the durability of the batteries must be comparable with the expected life of the vehicle for consumer acceptance.

Lithium (Li) battery technology, because of its high energy density and high specific energy, is one of the most promising candidates for vehicle applications. The development of these electrochemical storage systems is underway in large public and private programs. Their principle 
objectives are to eliminate or minimize the principal hurdles impacting lithium-based batteries: safety, cycle and calendar life and costs. Substantial progress has been made in $\mathrm{Li}$ technology, with many cell chemistries and designs and other engineering solutions being proposed. All are based on the use of $\mathrm{Li}$ as the main active material. However, the performance versus time and temperature behavior and the degradation mechanisms of these systems are not fully understood. Many testing programs are being carried out to improve the general understanding of these battery systems, which, in turn, will improve cell design and fabrication and battery integration into the vehicle.

Battery testing, in general, and, in particular, of Li batteries, to determine the performance and life characteristics in the various applications is a time-consuming and costly process that is not yet well developed. Many research organizations in many countries are working on aspects of testing and have amassed a large amount of data already. The data are normally acquired using different testing methods and may not be readily compared. In addition, some of the data are not widely available. This has limited the availability of detailed information. Hence, it can be very difficult to obtain data, which could be used by battery developers and end users, such as system integrators and electric vehicle manufacturers.

There are many examples of parallel testing activities that are poorly coordinated. For example, in Europe, the "Lithium Batteries Evaluation and Research - Accelerated Life Test Direction" Program involved six European testing institutes and was working up to mid2006 to investigate the degradation mechanisms of a few Li cells that were available at that time. In the US, some national laboratories are carrying out testing activities to support $\mathrm{Li}$ research and advanced technology development. In Japan, JARI and CRIEPI are testing Li cells and batteries for research and to define standards. The International Energy Agency (IEA) is an autonomous body that was established in November 1974 within the framework of the Organization for Economic Co-operation and Development to provide credible, balanced, objective information on energy issues and technologies to its member countries. The IEA does not seek to advocate particular technologies, only to report objectively on them. As part of the IEA activity, an Implementing Agreement for Hybrid and Electric Vehicles was started in 1993. Its goal was to produce and disseminate balanced, objective information about advanced vehicle technologies, including electric, hybrid and fuel cell vehicles. It is a working group of Governments and research organizations of member countries of the IEA. Currently, Austria, Belgium, Canada, Denmark, Finland, France, Ireland, Italy, the Netherlands, Spain, Sweden, Switzerland, Turkey, the United Kingdom and the United States of America are actively participating in this Implementing Agreement.

International co-operation presents many advantages: the comparison of data from different countries would be simplified; the information would be complete and would contain feedback on technology trends; testing resources could be better used; and the production of testing standards could be accelerated. Indeed, with a common standard, data collection and reporting would be directly comparable.

This paper represents the first step in the international collaboration, the collection of the battery performance and life test procedures used in the US, Japan and Europe. Once the procedures have been collected, they will be analyzed and compared, searching for common themes. If necessary, some test methods will be compared experimentally by performing those tests on a common battery in the labs involved. The goal of the experiment is two-fold. The first is to directly compare the results from one lab to another (i.e., to "calibrate" the labs). The second is to determine if one test method stresses the battery more than the others. If this is found, then the experimental results will also show how large the difference is.

\section{Test Procedures}

\subsection{Battery Test Procedures in the US}

Battery performance and life testing in the US is application-driven. The current focus is on three applications: HEVs, PHEVs and EVs. However, for the sake of simplicity, only the test methods for the PHEV and EV applications at the precompetitive stage will be discussed. The general philosophy behind the tests is to obtain enough data in a limited amount of time to gauge the performance of the battery and aging characteristics without exhausting it. Thus, the procedures used employ accelerated aging techniques. A test, itself, consists of three parts:

\footnotetext{
The work at Argonne and Idaho was performed under the auspices of the US Department of Energy, Office of Vehicle Technologies, Hybrid and Electric Systems, under Contract Nos. DE-AC02-06CH11357 and DE-AC07-05ID14517, respectively.
} 
characterize the performance of the battery; age it under controlled conditions for a period of time; and measure changes in performance by repeating portions of the characterization tests. These last tests are also known as reference performance tests or RPTs.

\subsubsection{PHEV Testing}

PHEV battery development for the US Advanced Battery Consortium (USABC) ${ }^{2}$ is focused on defining the appropriate battery targets for several different platforms and the development of standard test procedures to validate battery performance with respect to the battery targets. The Battery Test Manual for Plug-In Hybrid Electric Vehicles [1] defines a series of tests to characterize aspects of the performance or life behavior of batteries for PHEV applications. Tests are defined based on the Vehicle Technologies Program targets for plug-in hybrid electric vehicles, though it is anticipated these tests may be generally useful for testing other energy storage devices for plug-in hybrid vehicles. Although the test procedures are directly applicable to complete battery systems, most can also be applied to the testing of modules, cells or sub-scale cells with appropriate scaling.

Vehicle Technologies Program Energy Storage Targets are the primary driving force for the test procedures and methods defined in this manual. These targets are outlined in Table 1 for minimum PHEV battery, medium PHEV battery, and maximum PHEV battery performance. This table of targets is the primary basis for the test manual. Establishing or verifying battery performance in comparison to these targets is a principal objective of the test procedures defined in the manual. The intended vehicle platform for the minimum PHEV battery target is a sport utility vehicle with a vehicular mass of $2000 \mathrm{~kg}$ with an equivalent electric range of 10 miles $(16 \mathrm{~km})$; the medium PHEV battery target is a car with a vehicular mass of $1600 \mathrm{~kg}$ with an equivalent electric range of 20 miles $(32 \mathrm{~km})$; and the maximum PHEV battery target is a car with a vehicular mass of $1500 \mathrm{~kg}$ with an equivalent electric range of 40 miles (64 $\mathrm{km})$. An example of the PHEV operation philosophy is shown in Fig. 1.

The test procedures described in the manual are intended for use over a broad range of devices at various stages of developmental maturity. The application of the procedures is further complicated by the existence of three different sets of performance targets. The approach taken for these procedures is to define a small set of test profiles

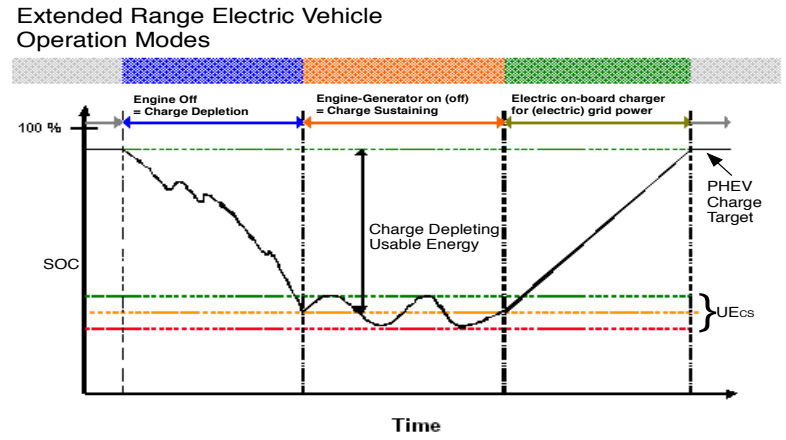

Figure 1: PHEV operation philosophy

based on the overall vehicle characteristics, independent of the size or capability of the device to be tested. These profiles are specified in terms of the characteristics of vehicle power demand. They can be used in various combinations, with the appropriate scaling factors, to define specific performance or cycle life tests for cells, modules or battery systems. Each profile is defined within the respective procedure described, because there is essentially a one-to-one relationship between test profiles and test procedures.

For PHEV battery testing, characterization tests establish the baseline performance and may include static capacity, hybrid pulse-power characterization (see Fig. 2 for test profile), self-discharge, cold cranking, thermal performance, and efficiency tests. Life testing establishes behavior over time at various temperatures, states of charge and other stress conditions and includes both cycle life (see Figs. 3 and 4 for $\mathrm{CD}=$ charge depleting and $\mathrm{CS}=$ charge sustaining test profiles, respectively) and calendar life testing. RPTs are performed every $600 \mathrm{~h}, 600 \mathrm{~h}$ and 30,000 cycles for the calendar and two cycle life tests, respectively.

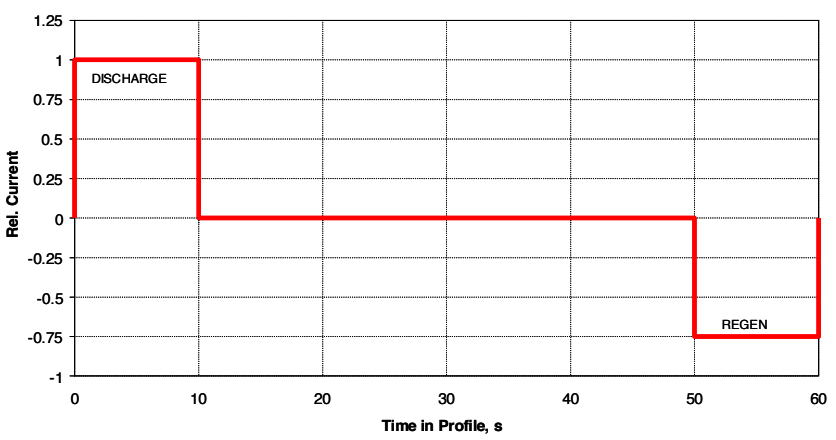

Figure 2: Hybrid pulse-power test profile. This profile is executed at every $10 \%$ DOD. ${ }^{2}$ The USABC consists of Ford, General Motors, Chrysler and
the US Department of Energy. 
Table 1: Energy Storage System Performance Targets for PHEVs (condensed)

\begin{tabular}{|c|c|c|c|c|}
\hline Characteristics at EOL (End-of-Life) & Unit & $\begin{array}{c}\text { Min PHEV } \\
\text { Battery }\end{array}$ & $\begin{array}{c}\text { Med PHEV } \\
\text { Battery }\end{array}$ & $\begin{array}{c}\text { Max PHEV } \\
\text { Battery }\end{array}$ \\
\hline Equivalent Electric Range & $\begin{array}{l}\text { Miles } \\
(\mathrm{km})\end{array}$ & $\begin{array}{c}10 \\
(16)\end{array}$ & $\begin{array}{c}20 \\
(32)\end{array}$ & $\begin{array}{c}40 \\
(64)\end{array}$ \\
\hline Peak Discharge Pulse Power (2 sec /10 s) & $\mathrm{kW}$ & $50 / 45$ & $45 / 37$ & $46 / 38$ \\
\hline Peak Regen Pulse Power (10 s) & $\mathrm{kW}$ & 30 & 25 & 25 \\
\hline Max. Current $-10 \mathrm{~s}$ & A & 300 & 300 & 300 \\
\hline $\begin{array}{l}\text { Available Energy for CD Mode, 10-kW } \\
\text { Rate }\end{array}$ & $\mathrm{kWh}$ & 3.4 & 5.8 & 11.6 \\
\hline $\begin{array}{l}\text { Available Energy for CS Mode, } 10-\mathrm{kW} \\
\text { Rate }\end{array}$ & $\mathrm{kWh}$ & 0.5 & 0.3 & 0.3 \\
\hline Minimum Efficiency & $\%$ & 90 & 90 & 90 \\
\hline Cold cranking power at $-30^{\circ} \mathrm{C}$ & $\mathrm{kW}$ & 7 & 7 & 7 \\
\hline CD Life & Cycle & 5,000 & 5,000 & 5,000 \\
\hline CS HEV Cycle Life, $50 \mathrm{Wh}$ Profile & Cycles & 300,000 & 300,000 & 300,000 \\
\hline Calendar Life, $35^{\circ} \mathrm{C}$ & Year & 15 & 15 & 15 \\
\hline Max System Wt & $\mathrm{kg}$ & 60 & 70 & 120 \\
\hline Max System Volume & Liter & 40 & 46 & 80 \\
\hline Max Voltage & Vdc & 400 & 400 & 400 \\
\hline Min Voltage & $\mathrm{Vdc}$ & $\begin{array}{l}>0.55 \times \\
V \max \end{array}$ & $>0.55 \times \mathrm{Vmax}$ & $>0.55 \times V \max$ \\
\hline Maximum Self-discharge & Wh/day & 50 & 50 & 50 \\
\hline Maximum System Recharge Rate $30^{\circ} \mathrm{C}$ & $\mathrm{kW}$ & $\begin{array}{l}1.4(120 \mathrm{~V} / \\
15 \mathrm{~A})\end{array}$ & $\begin{array}{l}1.4(120 \mathrm{~V} / \\
15 \mathrm{~A})\end{array}$ & $\begin{array}{l}1.4(120 \mathrm{~V} / \\
15 \mathrm{~A})\end{array}$ \\
\hline Temp Range & ${ }^{\circ} \mathrm{C}$ & -30 to +52 & -30 to +52 & -30 to +52 \\
\hline Survival Temp Range & ${ }^{\circ} \mathrm{C}$ & -46 to +66 & -46 to +66 & -46 to +66 \\
\hline Suggested Total Energy & $\mathrm{kWh}$ & 5.6 & 8.7 & 17.0 \\
\hline $\begin{array}{l}\text { Maximum System Production Price @ } \\
100 \mathrm{k} \text { units/yr }\end{array}$ & $\$$ & $\$ 1,700$ & $\$ 2,200$ & $\$ 3,400$ \\
\hline
\end{tabular}

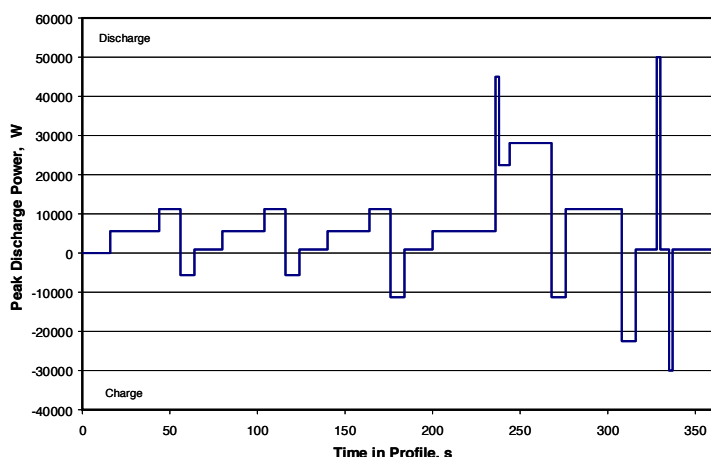

Figure 3: PHEV CD profile. Starting from about $90 \%$ $\mathrm{SOC}$, this profile is repeated until the scaled, goal CD energy is removed

\subsubsection{EV Testing}

The goals for EV battery development were originally based on an improved, dual-shaft electric propulsion (IDSEP) van [2, 3, 4, 5], which was similar in size and weight to a minivan. The IDSEP van weighed about $2400 \mathrm{~kg}$ and the battery system weight for the van was about $700 \mathrm{~kg}$ [2]. By using the ratio of the battery power needed to propel the vehicle to vehicle weight, the target vehicle was scaled to a fourpassenger, compact car, which weighed about $1800-2000 \mathrm{~kg}$, including the battery system [2, 3, 4 , 5]. By using a mathematical model of the vehicle, the battery development goals shifted from being based on the vehicle weight to being based on battery weight and volume. The goals for EV battery development were established by the USABC and are given in Table 2 [6]. The test procedures were developed based on these goals. The test procedures described in the manual are meant to be independent of the device being tested. Thus, they can be used with any battery technology at various maturity levels. As indicated in Table 2, as the technology matures, the goals change. The manual contains procedures to characterize many facets of battery behavior, ranging from vibration response to life.

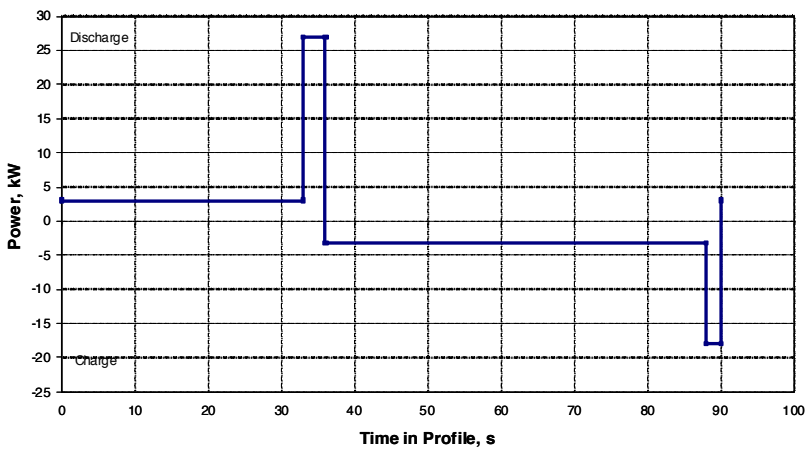

Figure 4: PHEV CS profile (minimum PHEV battery)

For the purposes of this paper, the discussion will be limited to those procedures that are necessary to characterize the electrochemical performance and 
life of a battery. The life of a battery can be further divided into calendar and cycle life. Both will be discussed further below.

Table 2: USABC EV battery goals.

\begin{tabular}{|c|c|c|}
\hline \multirow[b]{2}{*}{ Parameter } & \multicolumn{2}{|c|}{ Target } \\
\hline & Mid-Term & $\begin{array}{l}\text { Long } \\
\text { Term }\end{array}$ \\
\hline Power density, W/L & 460 & 600 \\
\hline $\begin{array}{l}\text { Specific power (discharge; } \\
80 \% \text { DOD for } 30 \mathrm{sec} \text { ), W/kg }\end{array}$ & 300 & 400 \\
\hline $\begin{array}{l}\text { Specific power (regen; } 20 \% \\
\text { DOD for } 10 \mathrm{sec} \text { ), W/kg }\end{array}$ & 150 & 200 \\
\hline Energy density at $\mathrm{C} / 3$ rate, $\mathrm{Wh} / \mathrm{L}$ & 230 & 300 \\
\hline $\begin{array}{c}\text { Specific energy at } \mathrm{C} / 3 \text { rate, } \\
\mathrm{Wh} / \mathrm{kg}\end{array}$ & 150 & 200 \\
\hline $\begin{array}{c}\text { Specific Energy: Specific Power } \\
\text { ratio }\end{array}$ & $2: 1$ & $2: 1$ \\
\hline Total pack size, $\mathrm{kWh}$ & 40 & 40 \\
\hline Life, years & 10 & 10 \\
\hline Cycle life ( $80 \%$ DOD), cycles & 1,000 & 1,000 \\
\hline Power and capacity degradation, & 20 & 20 \\
\hline Operating environment & $\begin{array}{l}-40 \text { to } 50^{\circ} \mathrm{C} \\
(20 \% \\
\text { performance } \\
\text { loss; } 10 \% \\
\text { desired })\end{array}$ & $\begin{array}{l}-40 \text { to } \\
85^{\circ} \mathrm{C}\end{array}$ \\
\hline Normal recharge time, $\mathrm{h}$ & 6 & 3 to 6 \\
\hline Fast recharge time & $\begin{array}{c}20-70 \% \mathrm{SOC} \\
\text { in }<30 \mathrm{~min}\end{array}$ & $\begin{array}{l}40-80 \% \\
\text { SOC in } \\
15 \text { min }\end{array}$ \\
\hline $\begin{array}{c}\text { Selling price }(10,000 \text { units } @ 40 \\
\text { kWh }), \$ / k W h\end{array}$ & $<150$ & $<100$ \\
\hline
\end{tabular}

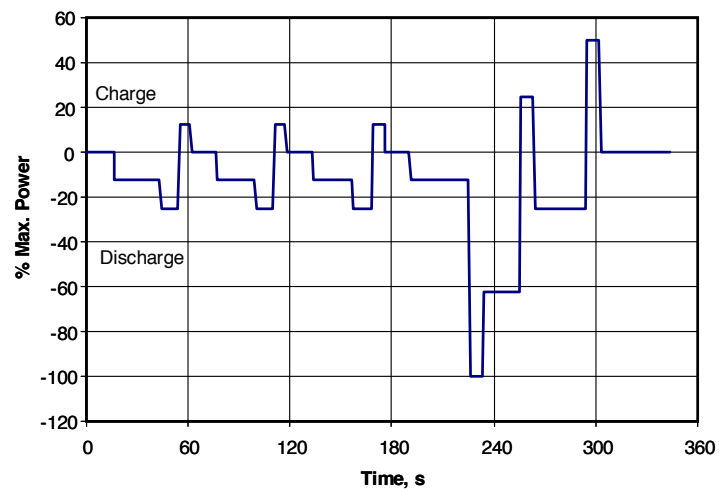

Figure 5: Dynamic Stress Test Profile. The maximum discharge power peak is scaled to $80 \%$ of the peak power available at $80 \%$ depth of discharge

The initial characterization consists of measuring its capacity and energy density under constantcurrent (i.e., at $\mathrm{C} / 3, \mathrm{C} / 2$ and $\mathrm{C} / 1$ rates) conditions and by using the dynamic stress-test profile (DST, see Fig. 5), its self-discharge rate, and its peak power (see Fig. 6). From the data generated during the peak power test, the power capability of the battery is defined as the minimum value calculated from Equations (1), (2), and (3),

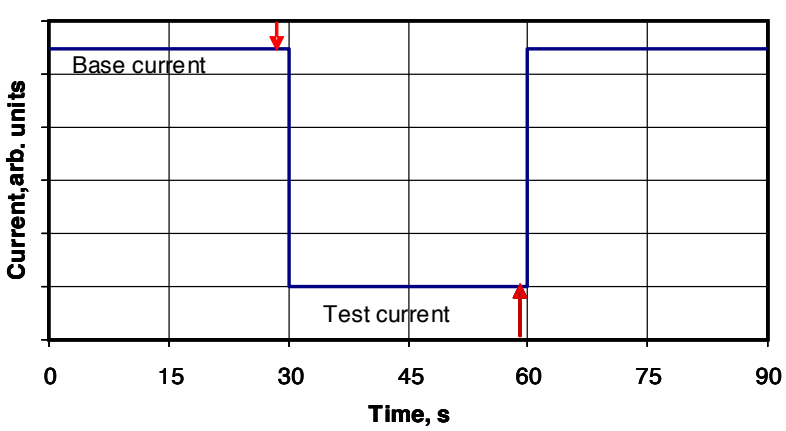

Figure 6: Profile used to measure peak power at every $10 \%$ DOD. The arrows indicate the points for measuring voltage $(\mathrm{V})$ and current (I). From these points, $R=\Delta V / \Delta \mathrm{I}$

$$
\begin{aligned}
& P_{n}=-\frac{2}{9} \frac{V_{I R-\text { free }}}{R_{n}} \\
& P_{n}=-V_{\text {lim }} \frac{V_{I R-f r e e}-V_{\text {lim }}}{R_{n}} \\
& P_{n}=-I_{\max }\left(V_{\text {IR-free }}+R_{n} \times I_{\max }\right),
\end{aligned}
$$

where $P_{\mathrm{n}}$ is peak power at $\mathrm{n} \% \mathrm{DOD}, V_{\mathrm{IR}-\text { free }}$ is the $\mathrm{iR}$ corrected voltage at a given $\% \mathrm{DOD}, R_{\mathrm{n}}$ is resistance at $\mathrm{n} \% \mathrm{DOD}, V_{\text {lim }}$ is the limiting discharge voltage and $I_{\max }$ is the maximum current for the battery. The end-of-test occurs when the peak power at $80 \%$ DOD or the battery capacity decreases below $80 \%$ of its rated value. At that time, the plots of $P_{80}$ calculated from Equations 1, 2 , and 3 vs. time usually converge and the measured power is reported.

As mentioned above, the life of a battery can be measured in terms of its calendar life (a storage test, no cycling) or cycle life. Calendar life testing can be performed at many different \%DOD and temperatures. Typically, it is performed at low $\% \mathrm{DOD}$ and in the temperature range of 25 to $60^{\circ} \mathrm{C}$. RPTs are performed every 28 days at $25^{\circ} \mathrm{C}$. Cycle life testing uses the DST profile, scaled for the power characteristics and repeated many times, to discharge the battery from 0 to $80 \%$ DOD, followed by recharging according to the developer's recommendations. Increasing the temperature at which the battery is cycled will further increase the rate of performance decline. In an EV test, RPTs are conducted every 50 cycles at $25^{\circ} \mathrm{C}$.

\subsection{Battery Test Procedures in Japan}

Since 2007, JARI, CRIEPI and National Institute of Advanced Industrial Science and Technology (AIST) have been developing a cycle-life test (CLT) procedure for lithium-battery technology, which accounts for actual usage conditions [7]. 
This development was conducted as part of the "Development of High-performance Battery System for Next-generation Vehicles (Li-EAD)" project [8] undertaken by New Energy and Industrial Technology Development Organization (NEDO) in Japan. This section discusses the rationale behind the more-recent CLT profile development in Japan.

\subsubsection{Development Targets of the CLT Profile}

From the results using the existing CLT profile, the targets for the development of the profile were as follows.

- The battery load should be based on that measured from the vehicle during a transient driving cycle (vehicle chargedischarge data, VCDD). This will allow the estimation of performance degradation, which occurs during driving.

- The CLT profile should be universal and not specific to a certain nation or region. Thus, the CLT profile was formulated using all the VCDDs of the subject vehicles driven according to the emission and fuel economy certification test cycles of Japan, the U.S. and Europe (i.e., JC08, UDDS and NEDC).

- The test procedure should be as simple as possible to enable the use of widelyavailable battery testing equipment and to facilitate the analysis of the degradation factors. Specifically, the minimum duration of CLT profile should be 2 seconds and the CLT profile should consist of rectangular waveforms and the smallest number of steps.

\subsubsection{Profile Development}

Using the results available, the profile that captured the usage characteristics of a vehicle was very complex. It, therefore, needed to be simplified in order to meet our third development goal (vide supra). The method we used to simplify the profile is described below.

\subsubsection{Extraction of Relevant Parameters}

The following six parameters were considered important in the evaluation of the cycle life of a battery.

$$
\text { a) } \begin{aligned}
I_{\max } & : \text { Max. current, } \mathrm{A} \\
& \text { or } \\
P_{\max } & : \text { Max. power, } \mathrm{W}
\end{aligned}
$$
b) $Q_{\text {tot }} \quad$ : Charge-discharge electricity, Ah or
$E_{\text {tot }} \quad$ : Charge-discharge energy, $\mathrm{Wh}$
c) $R_{\mathrm{SOC}}:$ SOC range of charge-discharge, $\%$
d) $t_{\text {rest }}:$ Rest time ratio, $\%$
e) $H_{\text {gen }}:$ Amount of heat generation, J
f) $T_{\text {rise }}:$ : Battery temperature rise, $\Delta^{\circ} \mathrm{C}$

In a given CLT profile, the parameters a), b), c) and d) relate to the structural changes and relaxation of the electrode active materials. The parameters a), d), e) and f) relate to the heat generation and rejection from the battery.

From the viewpoint the vehicle, the battery burden can be expressed in terms of electric power instead of current. Since the voltage can vary with $\mathrm{Li}$ battery chemistries, the current may be different even though the power has not changed. Consequently, power values were used to define the profile. The rationale for the selected parameters and some of their definitions are given below.

a) With larger values of the maximum power, $P_{\max }$, the rate of performance degradation should increase

b) The charge-discharge energy, $E_{\text {tot }}$, is defined in Equation 6.

$$
E_{\text {tot }}=\int|P(t)| d t
$$

c) The range of the state of charge (SOC), $R_{\mathrm{soc}}$, during charging is constant if the upper and lower limits of SOC are defined during a cycle life test.

d) The definition of the rest time ratio, $t_{\text {rest }}$, is given in Equation (7).

$$
t_{\text {rest }}=\sum t(I=0) / t_{\text {cycle }},
$$

where $t(I=0)$ is the time during the cycle where the current is off and $t_{\text {cycle }}$ is the time required for one cycle.

e) The amount of heat generated, $H_{\text {gen }}$, is given in Equation (8). Assuming that both the internal resistance, $R$, and the voltage, $V$, are constant throughout the charge-discharge process, $H_{\text {gen }}$ can also be defined using $P$ instead of $I$.

f) The change in the battery temperature is determined by the balance between $H_{\text {gen }}$, and heat rejection, $H_{\text {rad }}$. As shown in Equation (8), the value of $H_{\text {gen }}$ is intrinsic to the battery and CLT profile. However, since amount of heat 
rejected can be variable and is determined by the ambient conditions of the battery, $H_{\text {rad }}$ was excluded from the CLT parameters.

$$
H_{g e n}=\int R[I(t)]^{2} d t=a \int[P(t)]^{2} d t
$$

It is evident from the above that, to simplify a CLT profile for PHEV batteries, the timeaveraged values of the four parameters, $P_{\max }, E_{\text {tot }}$, $t_{\text {rest }}$, and $H_{\text {gen }}$, must be equated to the VCDD.

\subsubsection{CLT Profile Simplification Method}

Based on the discussion in the preceding sections, the following three steps were taken to simplify the CLT profile.

1. Calculate the Average Values of the Certification Driving Cycles from Japan, the U.S., and Europe

To formulate a CLT profile capable of representing the 42 total trips contained in the JC08, UDDS and NEDC profiles in a single profile, the average times of "Trip+Idle" and "Trip" in the three test cycles were calculated. As shown in Table 3, the average length of time for "Trip+Idle" was 89.4 seconds and that of "Trip" was 67.7 seconds, adding the three test cycles together. As shown in Fig. 7, the average of the "Trip + Idle" times equaled the time of the CLT profile, and the average of "Trip" times equaled that between vehicle start and vehicle stop (i.e., from discharge start to charge end). The average vehicle speed was $29.89 \mathrm{~km} / \mathrm{h}$.

\section{VCDD Sorting and Compression}

Procedures (1) and (2) were used to compress data and to formulate the target CLT profile. An example of this compression and formulation process is shown in Fig. 8.

Table 3: Average of three driving cycles

\begin{tabular}{cccccc}
\hline Item & Unit & JC08 & UDDS & NEDC & Integrated \\
\hline $\begin{array}{c}\text { Test time } \\
\text { Driving } \\
\text { distance }\end{array}$ & $\mathrm{s}$ & 1204 & 1371 & 1180 & 3755 \\
$\begin{array}{c}\text { Number of trips } \\
\text { Average of } \\
\text { (trip+idle) }\end{array}$ & piece & 11 & 18 & 13 & 42 \\
$\begin{array}{c}\text { Average trip } \\
\text { time }\end{array}$ & $\mathrm{s}$ & 109.5 & 76.2 & 90.8 & 89.4 \\
Average speed $^{2}$ & $\mathrm{~km} / \mathrm{h}$ & 24.43 & 31.48 & 33.60 & 29.89 \\
\hline $\begin{array}{l}\text { Average of (trip+idle) } \\
\text { Average trip time }\end{array}{ }^{2}=\mathrm{Summation}$ of each trip time/Number of trips &
\end{tabular}

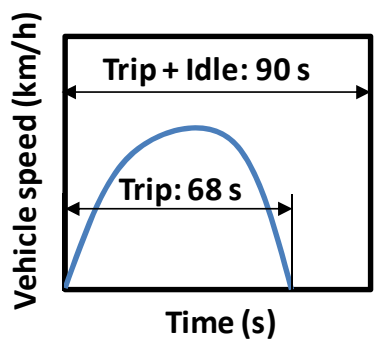

Figure 7: Schematic of average driving cycle

(1) The VCDDs of JC08, UDDS and NEDC were concatenated, forming a 3,755-second-long power density vs. time dataset.

(2) The dataset was then sorted by power density from large to small values, irrespective of driving pattern. The original dataset was, thus, compressed into 90-seconds.

\section{Simplification}

The target CLT profile was constructed by applying the following rules to the compressed data.

(1) The wave profile must be rectangular, and the minimum time for the profile must be at least 2 seconds. Power density was used to initially scale the profile.

(2) There will be two steps, high power, $P_{\mathrm{H}}$, and low power, $P_{\mathrm{L}}$, in each of the charge and discharge half-cycles. Two-second discharge and charge data were extracted from each of the 3 test cycles for a total of 6 seconds of VCDD. The average value of the 6-second total was then defined as the maximum power, $P_{\max }$.

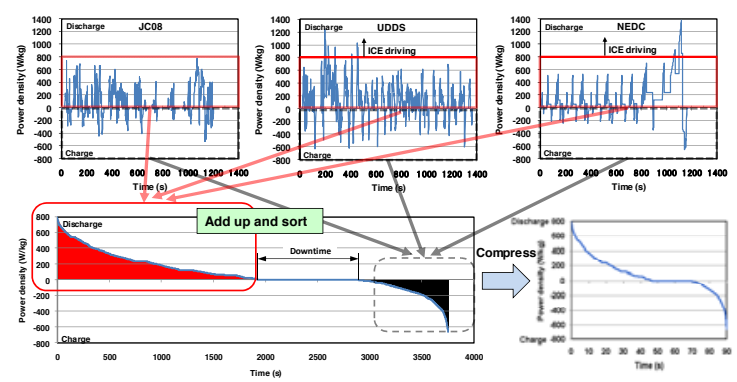

Figure 8: Sorting and compression of VCDD

(3) By adjusting the time ratio of the high and low steps $\left(t_{\mathrm{H}}: t_{\mathrm{L}}\right)$ and the value of $P_{\mathrm{L}}, E_{\text {tot }}$ and $H_{\text {gen }}$ will be made as equal as possible to the compressed data without $t_{\text {rest }}$ (Fig. 9).

(4) To match the time from the start of discharge to end of charge with that from the vehicle's starting/acceleration to deceleration/stopping (68 seconds in this study), the data on the charge side 
will be moved forward. To match discharge data, the compressed data will be rearranged from inverted ' $L$ ' to non-inverted 'L' (Fig. 10).

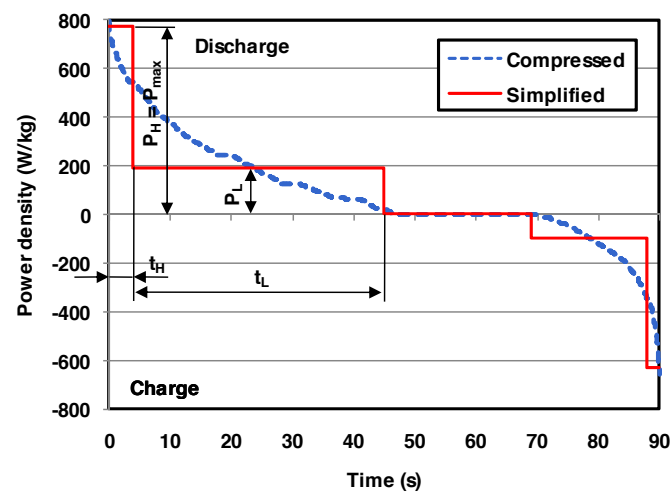

Figure 9: Simplification of compressed data

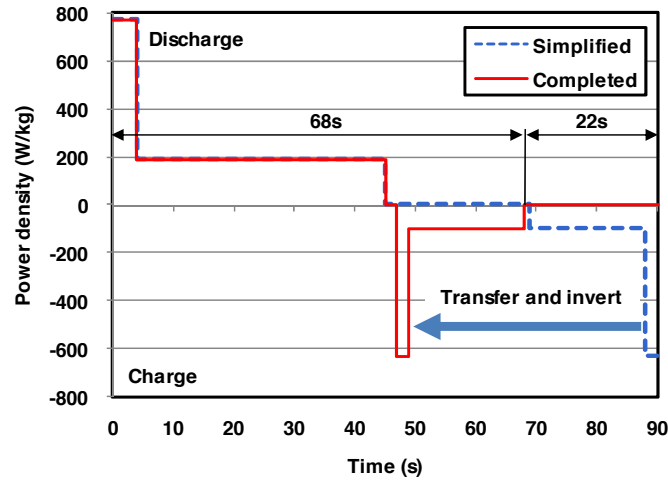

Figure 10: Transfer and invert of charge side data

\subsubsection{Formulation of CLT Profiles}

\subsubsection{Acquisition of VCDD}

VCDDs were acquired by the following methods for the JC08, UDDS and NEDC driving cycles:

- HEV: The battery output was measured on a chassis dynamometer using a representative passenger car with a mass of $1,260 \mathrm{~kg}$.

- EV and PHEV: The battery output was calculated, assuming a representative passenger car with a mass of $1,250 \mathrm{~kg}$.

\subsubsection{Generalization of CLT Profiles}

The CLT profiles developed above were based on VCDDs of specific, electrically-propelled vehicles (EPVs). For greater utility, the CLT profiles must be generalized to all $\mathrm{Li}$ batteries. The generalization method is discussed below.

\subsubsection{Estimation of Maximum Discharge Rate}

The maximum discharge rates of parallel HEVs with one motor and those of series-connected HEVs and EVs can be represented by Equation (9) below, if the voltage drop caused by internal resistance is neglected.

$$
R_{\text {max_discharge }}=\frac{P_{\text {motor }}-P_{\text {gen }}}{V_{\text {batt }} \times \eta_{\text {motor }} \div 1000 \times \mathrm{C}_{\text {batt }}}
$$

$R_{\text {max discharge: }}$ maximum discharge rate, $\mathrm{C}$

$P_{\text {motor }}$ : maximum motor power, $\mathrm{W}$

$P_{\text {gen }}$ : maximum generator power, $\mathrm{W}$

$V_{\text {batt }}$ : battery open circuit voltage, $\mathrm{V}$

$\eta_{\text {motor }}$ : motor efficiency

$C_{\text {batt }}$ : battery rated capacity, $\mathrm{Ah}$

The maximum battery discharge rates for HEVs and EVs, which have the specifications shown in Table 4, were estimated by using Equation (9). These results are also given in Table 4 and are plotted in Fig. 11. From Fig. 11, the maximum discharge rate decreased as the battery capacity increased.

Table 4: Specifications of existing HEVs and EVs

\begin{tabular}{ccccccc}
\hline $\begin{array}{l}\text { Vehicle } \\
\text { symbol }\end{array}$ & $\begin{array}{c}\text { Motor } \\
\text { Power } \\
(\mathrm{kW})\end{array}$ & $\begin{array}{c}\text { Generator } \\
\text { Power } \\
(\mathrm{kW})\end{array}$ & $\begin{array}{c}\text { Battery } \\
\text { Voltage } \\
(\mathrm{V})\end{array}$ & $\begin{array}{c}\text { Battery } \\
\text { capacity } \\
(\mathrm{Ah})\end{array}$ & $\begin{array}{c}\text { Estimated } \\
\text { max. } \\
\text { current, } \\
(\mathrm{A})\end{array}$ & $\begin{array}{c}\text { Estimated } \\
\text { max. } \\
\text { discharge } \\
\text { rate, (C) }\end{array}$ \\
\hline HEV-L1 & 17 & 0 & 346 & 3 & 54.6 & 18.2 \\
HEV-L2 & 29 & 0 & 346 & 5.5 & 93.1 & 16.9 \\
HEV-L3 & 35 & 0 & 346 & 5.5 & 112.4 & 20.4 \\
HEV-L4 & 158 & 40 & 634 & 22 & 206.8 & 9.4 \\
EV-L1 & 40 & 0 & 346 & 27 & 128.5 & 4.8 \\
EV-L2 & 47 & 0 & 330 & 50 & 158.2 & 3.2 \\
EV-L3 & 100 & 0 & 355 & 95 & 313.0 & 3.3 \\
EV-L4 & 24 & 0 & 120 & 90 & 222.2 & 2.5 \\
EV-L5 & 30 & 0 & 370 & 70 & 90.1 & 1.3 \\
\hline
\end{tabular}

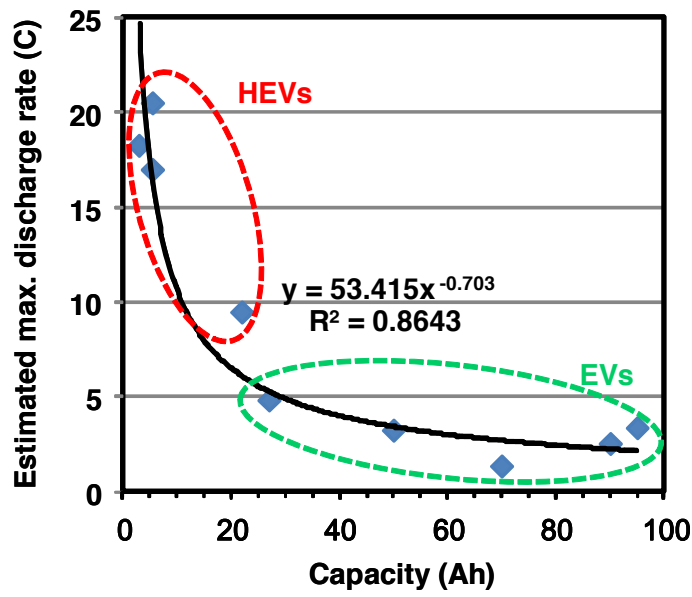

Figure 11: Estimated maximum discharge rate vs. battery capacity. The solid curve represents a least-squares fit of the data points shown 


\subsubsection{Construction of Generalized CLT Profiles}

Examples of generalized, PHEV CLT profiles are shown in Fig. 12, with the vertical axis given in terms of relative discharge rates. From Fig. 12, the absolute discharge rate can be obtained by using Equation (10).

$\boldsymbol{R}_{\text {discharge }}=\boldsymbol{R}_{\text {relative_discharge }} \times \boldsymbol{a} \cdot \boldsymbol{C}_{\text {batt }}^{b}$

$R_{\text {discharge: }}$ discharge rate, $\mathrm{C}$

$R_{\text {relative_discharge: }}$ relative discharge rate

$C_{\text {batt }}$ : battery rated capacity, Ah

From a least-squares fit of the data in Fig. 12, the initial values of $a$ and $b$ were 53.415 and -0.703 , respectively. Clearly, additional work is needed to verify these values. Data for constructing the profiles shown in Fig. 12 and for other EPVs are given in Table 5.

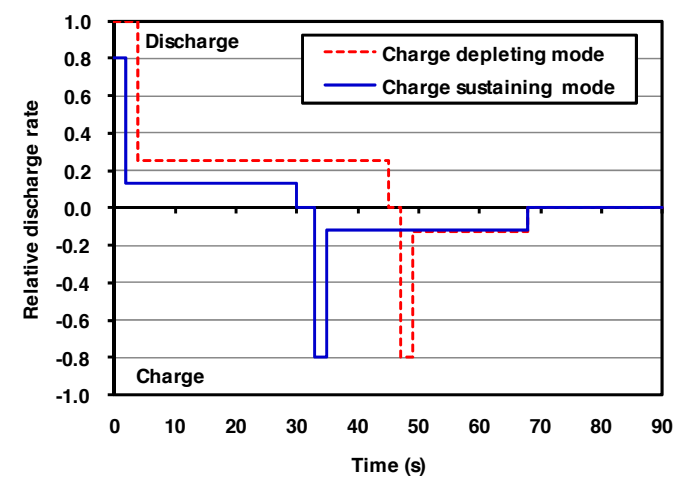

Figure 12: Generalized CLT profiles for a PHEV battery

Table 5: Generalized CLT profile data for EPVs

\begin{tabular}{ccccc}
\hline $\begin{array}{c}\text { Vehicle } \\
\text { type }\end{array}$ & $\begin{array}{c}\text { Step } \\
\text { No. }\end{array}$ & $\begin{array}{c}\text { Step time } \\
(\mathrm{s})\end{array}$ & $\begin{array}{c}\text { Cumulative } \\
\text { time } \\
(\mathrm{s})\end{array}$ & $\begin{array}{c}\text { Relative } \\
\text { discharge } \\
\text { rate }\end{array}$ \\
\hline & 1 & 4 & 4 & 1.000 \\
PHEV & 2 & 41 & 45 & 0.250 \\
CD Mode & 3 & 2 & 47 & 0.000 \\
& 4 & 2 & 49 & -0.800 \\
& 5 & 19 & 68 & -0.125 \\
& 6 & 22 & 90 & 0.000 \\
\hline \multirow{4}{*}{ PHEV } & 1 & 2 & 2 & 0.800 \\
CS Mode & 2 & 28 & 30 & 0.135 \\
& 3 & 3 & 33 & 0.000 \\
& 4 & 2 & 35 & -0.800 \\
& 5 & 33 & 68 & -0.115 \\
HEV & 6 & 22 & 90 & 0.000 \\
\hline & 1 & 2 & 2 & 1.000 \\
& 2 & 28 & 30 & 0.170 \\
& 3 & 3 & 33 & 0.000 \\
& 4 & 2 & 35 & -1.000 \\
EV & 5 & 33 & 68 & -0.145 \\
& 6 & 22 & 90 & 0.000 \\
\hline & 1 & 2 & 2 & 1.000 \\
& 2 & 43 & 45 & 0.170 \\
& 3 & 2 & 47 & 0.000 \\
& 4 & 2 & 49 & -0.450 \\
& 5 & 19 & 68 & -0.070 \\
& 6 & 22 & 90 & 0.000 \\
\hline
\end{tabular}

\subsection{Battery Test Procedures in the EU}

In the second half of the 1990's, the first testing procedures $[9,10,11]$ were agreed to and used in a subsequent EC project, ASTOR ${ }^{3}$. This three-year project started in 2001 with the aim of experimentally evaluating and analyzing battery and super-capacitor technologies, such as advanced lead/acid, nickel/metal-hydride, and lithium-ion. Almost in parallel, another research project was awarded by the EC with the objective to develop and validate accelerated life test procedures for lithium battery technologies. This project, named LIBERAL (Lithium Battery Evaluation And Research - Accelerated Life Test Direction), started in 2002 [12] and completed in 2006. The work on test procedure development has continued within the $7^{\text {th }}$ RTD Framework Program, in HELIOS (High Energy Lithium-Ion Storage Solutions) and HCV (Hybrid Commercial Vehicles) projects. The emphasis here was batteries for EV, HEV and PHEV applications. For simplicity, this section describes only the results from the LIBERAL project.

\subsubsection{Assessment of degradation mechanisms}

Initially, the most significant factors which accelerated the performance degradation of lithium batteries were identified and ranked in order of their relative importance [13]. The most important factors were as follows.

- Temperature: High temperatures accelerated the degradation, but low temperatures also had an effect.

- SOC: High and low states of charge may reduce life.

- Materials parameters: the ageing and degradation effects of some accelerating factors strongly depend on the cell materials.

\subsubsection{Accelerated Life Testing Procedures}

Two categories of tests, described below, were designed and validated for high-power and highenergy lithium batteries. For both types of batteries, a common storage (calendar life) test could be used. Periodically, the state-of-health of the cells was monitored, as described below, and included capacity and internal resistance measurements at room temperature) and, occasionally, electrochemical impedance spectroscopy. From these results, a mathematical,

\footnotetext{
${ }^{3}$ ASTOR $=$ Assessment and Testing of Advanced Energy Storage Systems for Propulsion and other Electrical Systems in Passenger Cars
} 
semi-empirical model based on the impedance spectra could be developed [14].

\subsubsection{High-energy cycling}

Fig. 13 shows a high energy profile for life cycling. Here, the maximum current pulse was, in terms of absolute value, at the $2-\mathrm{C}$ rate. A similar profile can be constructed that contains a 1-C maximum current pulse. These profiles were based on the power profiles of the previous EUCAR HEV power-assist test procedures which referred to the defined, reference vehicles. A discharge cycle, typically, started at $0 \%$ and stopped at $80 \%$ DOD. The battery was then recharged according to the developer's recommendations. To further accelerate the tests, the cycling could be performed at elevated temperatures, with reference tests every 6 weeks.

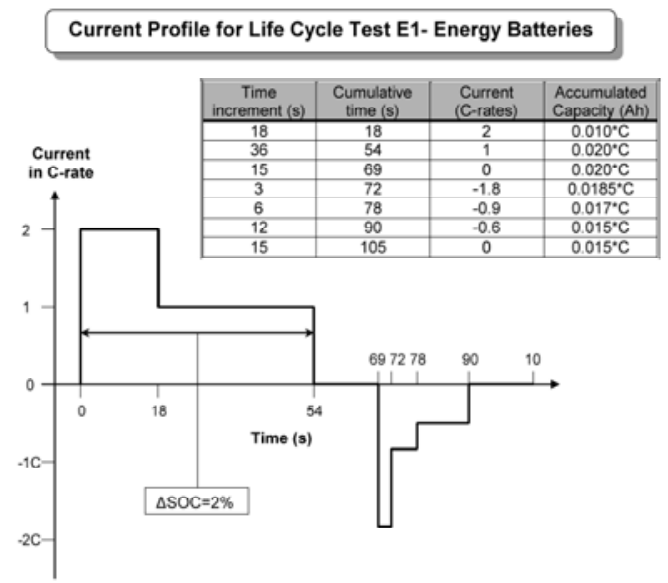

Figure 13: Current profile for high-energy batteries, showing a maximum current of $2 \mathrm{C}$ and $2 \%$ SOC swing. Approximately 53 profiles are needed to discharge the battery to $80 \%$ DOD

\subsubsection{High-power cycling}

The basic profile for this test is given in Fig. 14 and shows a maximum current of $10 \mathrm{C}$. Variations of this profile have been used. Here, the profiles are similar in appearance, but the timings and the SOC limits differ. For example, this test could be performed with SOC limits of $60-50 \%$ or $70-50 \%$. Reference tests were performed every 6 weeks.
Power batteries: Current Profile P1 for Life Cycle Test

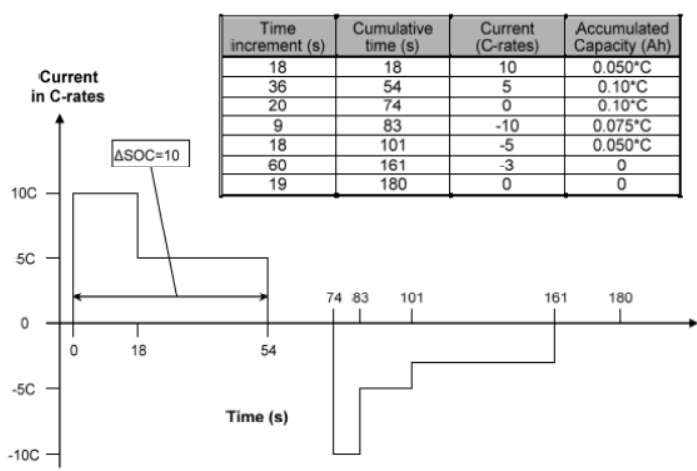

Figure 14: Current profile for high power batteries, high maximum current (10C) and normal SOC window (10\%).

\subsubsection{Calendar life}

The effects on ageing of time and elevated temperatures were identified with storage (or calendar life) tests. Typically, these tests are performed at a number of temperatures and at different SOCs (e.g., 50 and 100\%). Reference tests were performed every 42 days at $25 \mathrm{oC}$. The testing period was usually 6 months.

\subsubsection{Reference test}

The profile shown in Fig. 15 was used to determine the state-of-health of the batteries under test. From the results, key parameters, such as capacity, several internal resistances, the pulse power capability and the open circuit voltage, were measured or calculated. Optionally, EIS tests were carried out to support mathematical model development and validation.
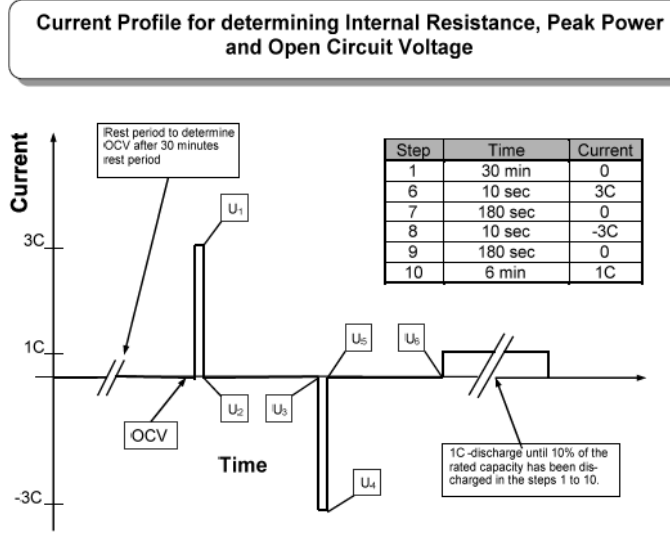

Figure 15: Current profile for determination of capacity, open circuit voltage, internal resistances and constant current power. 


\section{Conclusions}

This paper represents the first step in the international collaboration to agree on a set of international testing protocols. Currently, each group uses somewhat different test protocols to establish life predictions for batteries in PHEV and EV applications. Each approach has intrinsic assumptions. Based on these assumptions, the resulting test procedures from one approach may stress the battery more than those from the others. Clearly, a careful comparison of these procedures is needed to determine the similarities and differences between them. Some experimental work may be needed to determine the magnitude of the differences which may be present in the test results.

\section{References}

[1] Battery Test Manual for Plug-In Hybrid Electric Vehicles, INL/EXT 07-12536, June 2010.

[2] G. H. Cole, A Simplified Battery Discharge Profile Based Upon the Urban Driving Schedule, Proc. EVS9, EVS88-078, November 13-16, 1988, Toronto, Ontario, Canada.

[3] G. H. Cole, A Generic SFUDS Battery Test Cycle for Electric Road Vehicle Batteries, SAE Technical Paper Series, 891664, pp. 59-63, Future Transportation Technology Conference and Exposition, Vancouver, BC, Canada, August 7-10, 1989.

[4] A. F. Burke and G. H. Cole, Application of GSFUDS to Advanced Batteries and Vehicles, Proc. $10^{\text {th }}$ International Electric Vehicle Symposium, Hong Kong, December 3-5, 1990, pp. 411-420.

[5] G. H. Cole and G. L. Hunt, Relating Vehicle Performance and Battery Requirements, Abstracts from the $184^{\text {th }}$ Electrochemical Society Meeting, October 12, 1993, New Orleans, LA.

[6] Electric Vehicle Battery Test Procedure Manual, Rev. 2, January 1996.

[7] K. Morita et al., Development of Cycle Life Test Profiles of Lithium-ion Batteries for Plug-in Hybrid Electric Vehicles, Proc. EVS-24, May 13-16, 2009, Stavanger, Norway.

[8] H. Hirose, Activities for NEDO's Project "R\&D of Fundamental Technologies on High Performance Rechargeable Batteries for Next Generation Vehicles" by FC-EV Center, JARI Research Journal, Vol. 30, No. 4, 2008 (in Japanese).

[9] EUCAR Traction Battery Working Group, Specification of Test Procedures for Electric Vehicle Traction Batteries, December 1996.
[10] EUCAR Traction Battery Working Group, Specification of Test Procedures for Hybrid Electric Vehicle Traction Batteries, September 1998.

[11] EUCAR Traction Battery Working Group, Specification of Test Procedures for High Voltage Hybrid Electric Vehicle Traction Batteries, January 2005.

[12] W. Josefowitz et alii, EUCAR Assessment and Testing activities of advanced energy storage systems, AABC3, June 11-13, 2003, Nice, France.

[13] J. Vetter et alii, Ageing mechanisms in lithium-ion batteries, Journal of Power Sources Vol. 147, (2005) pp. 269-281.

[14] EUCAR Traction Battery Working Group et alii, Specification of Accelerated Life Test Procedures, LIBERAL Project, August 2006.

\section{Authors}

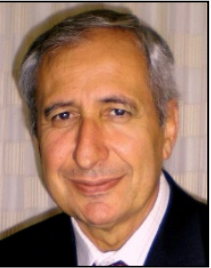

Dr. Mario Conte is the responsible for ENEA's Energy Storage Systems Coordination Unit. $\mathrm{He}$ is involved in national and international projects on batteries, supercapacitors, hydrogen storage and mobile and stationary applications. He is technical secretary of the Italian EV association and member of AVERE and WEVA and vice-chairman of the IEA IA on electric and hybrid vehicles.

Dr. Fiorentino Valerio Conte is energy storage group leader within AIT. He leads projects on energy storage

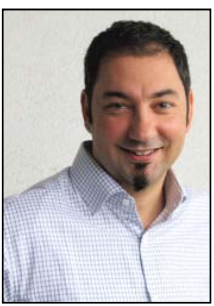
systems for HEVs and EVs. He joined AIT in 2003 after his $\mathrm{PhD}$ in Transportation at the University of Pisa. Dr. Conte has over 10 years of experience on advanced powertrains. Since 2005 he has been involved in the activities of the IEA IA on electric and hybrid vehicles.

Dr. Ira Bloom is the Manager of the Electrochemical Analysis and Diagnostics Laboratory at ANL. He is responsible for managing the battery and fuel cell test group and for data analysis. He holds a BS degree in

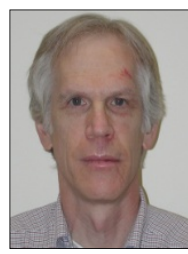
chemistry from Brown University (1978) and a PhD degree in inorganic chemistry from the University of Chicago (1983). He has twelve years of experience testing automotive-class batteries and analyzing the resulting data.

Mr. Kenji Morita is the Manager of the Performance Research, FC-EV 
Research Division at JARI. He is responsible for managing the performance research group of

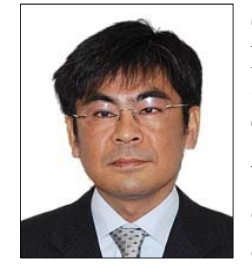
electrically propelled vehicles. He holds a BS degree in mechanical and system engineering from Toyota Technological Institute (1993). He has three years of experience testing automotive-class batteries and analyzing the resulting data.

Dr. Tomohiko Ikeya is the Leader of the Advanced Function Materials Sector at Materials Science Laboratory in CRIEPI. $\mathrm{He}$ is responsible for managing the application technologies for secondary batteries. At CRIEPI, he has studied the use of secondary batteries for electric vehicles and energy storage systems on the demand side. He holds a $\mathrm{BS}$ and a $\mathrm{PhD}$ degree in Applied Chemistry from Keio University (1989).

Mr. Jeffrey Belt is a senior Chemical Engineer in the Transportation Technology Department at INL. He is the chief responsible for the testing of advanced batteries and capacitors in the U.S. Department of Energy, FreedomCAR and Vehicle Technologies Program. He holds a Master Degree in Chemical Engineering from the University of Idaho (2007). He has 13 years of experience developing and testing batteries for automotive applications. 